\title{
ГЕОЭКОЛОГИЯ
}

УДК

661.183

\section{ФИЗИКО-ХИМИЧЕСКИЙ АНАЛИЗ ФОРМИРОВАНИЯ ПОРИСТОЙ СТРУКТУРЫ И ЭКСПЛУАТАЦИОННЫХ СВОЙСТВ ТЕРМОМОДИФИЦИРОВАННЫХ СОРБЕНТОВ ДЛЯ ОЧИСТКИ СТОЧНЫХ ВОД}

\author{
Ларина О.Г.* Северо-Кавказский федеральный университет, \\ Овчаров С.Н. г. Ставрополь, Россия,
} Калиниченко А.Ю. *oksdolgikh@yandex.ru

\begin{abstract}
Введение:
в статье поднята актуальная на сегодняшний день комплексная проблема загрязнения окружающей среды техногенными отходами и ее составляющая - поиск эффективных методов очистки сточных вод от нефти и продуктов ее переработки. Авторы предлагают использовать для ее решения перспективные сорбционные технологии. Номенклатура сорбционных материалов из года в год неуклонно расширяется, однако сдерживающими фракторами их повсеместного внедрения служат высокая стоимость, не всегда оптимальные эксплуатационные характеристики, экологическая безопасность утилизации насыщенных поглотителей. В статье оценивается возможность использования сорбентов на основе растительных отходов для очистки сточных вод от нестяного загрязнения. Четкое представление о физико-химических и механических свойствах исходных материалов служит необходимым условием определения рациональных путей их переработки. Термическое модифицирование сырья позволяет придать сорбентам эксплуатационные характеристики, требуемые применительно к конкретному типу загрязнителей. Цель работы заключалась в изучении влияния условий получения сорбентов на их способность очищать воду от нефтяного загрязнения.
\end{abstract}

Материалы и методы исследований:

сырьем для исследований служила подсолнечная лузга, подвергаемая карбонизации в бескислородных условиях. Использованы методы термического анализа, сканирующей электронной микроскопии, низкотемпературной адсорбции азота. Для оценки эксплуатационных свойств термомодифицированных сорбентов применялись весовые методы.

Результаты исследований и их обсуждение:

получена термограмма разложения лузги подсолнечной, дающая представление об особенностях процесса термического разложения растительных отходов в диапазоне $150-700{ }^{\circ} \mathrm{C}$. Исследованы значения выхода, плавучести, нефте- и водопоглощения сорбентов, наработанных в интервале температур от 200 до $600{ }^{\circ} \mathrm{C}$, определена величина их поверхности, особенности пористой структуры, позволяющие считать оптимальной карбонизацию при $300-400^{\circ} \mathrm{C}$.

Выводы:

пористая структура сорбентов оказывает непосредственное влияние на их эксплуатационные характеристики. Для эффективной очистки сточных вод от нефтяного загрязнения необходимы крупнопористые поглотители. Карбонизация растительного сырья приводит к увеличению сорбционной поверхности, ее гидрофобизации. Практическую значимость имеет оценка перспективы использования сорбентов на основе отходов для очистки сточных вод от различных типов загрязнителей.

Ключевые слова:

сорбенты, отходы, очистка сточных вод, карбонизация, сорбционные характеристики. 


\title{
PHYSICO-CHEMICAL ANALYSIS OF THE FOR- MATION OF POROUS STRUCTURE AND PER- FORMANCE PROPERTIES OF THERMALLY MODIFIED SORBENTS FOR WASTEWATER PURIFICATION
}

\author{
Larina O.G. Ovcharov S.N. Kalinichenko A.Yu. \\ North-Caucasian Federal University, Stavropol, Russia
}

Introduction:

\section{Materials and \\ Research results and discussion:}

methods of research: the raw material for the research was sunflower husk subjected to carbonization in oxygen-free conditions. The methods of thermal analysis, scanning electron microscopy, low-temperature nitrogen adsorption were used. For the assessment of operational properties of sorbents thermomodification applied weighting methods.

Conclusions:

Key words:

the thermogram of decomposition of sunflower husk, giving an idea of the features of the thermal decomposition of plant waste in the range of $150-700^{\circ} \mathrm{C}$. The values of yield, buoyancy, oil and water adsorption of sorbents, worked out in the temperature range from 200 to $600^{\circ} \mathrm{C}$, determined the value of their surface, the features of the porous structure, allowing to consider the optimal carbonation at 300 $400^{\circ} \mathrm{C}$.

the porous structure of sorbents has a direct impact on their performance properties. Large-scale absorbers are necessary for effective treatment of waste water from oil pollution. Carbonation of plant raw materials leads to an increase in the sorption surface, its hydrophobization. The practical significance of the perspective of the use of sorbents on the basis of wastes for purification of wastewater from different types of pollutants.

sorbents, waste, wastewater purification, carbonization, sorption characteristics.

the article raises the current complex problem of environmental pollution with technogene waste and its component - the search for effective methods of wastewater treatment from oil and its products. The authors propose to use the perspective of sorption technology. The range of sorption materials from year to year is steadily expanding, however the deterrent factors of their widespread introduction are the high cost, not always optimal performance, environmental safety of disposal of saturated absorbers. The article assesses the prospects of using sorbents based on plant waste for wastewater purification from oil pollution. A clear understanding of the physico-chemical and mechanical properties of the raw materials is a necessary condition for determining the rational ways of their processing. Thermal modification of raw materials allows giving the sorbents the performance characteristics required for a particular type of pollution. The aim of the work was to study the influence of sorbent production conditions on their ability to purify water from oil pollution.

\section{Введение}

Стремительный экспоненциальный рост объемов твердых, жидких и газообразных отходов техногенного происхождения вызывает все большее истощение невозобновимых природных ресурсов - полезных ископаемых и пресной воды. Сложившаяся на сегодняшний день эколого-экономическая ситуация обусловливает весьма интенсивный спрос на создание 
современных инновационных технологий, обеспечивающих рациональное обращение с отходами. Важной составляющей этой комплексной проблемы является поиск эффективных методов очистки сточных вод от основного спектра загрязнений - нефти и продуктов ее переработки, тяжелых металлов. Перспективным, но еще недостаточно востребованным направлением очистки сточных вод от нефтяного загрязнения, выступает использование сорбционных технологий $[1,2]$.

К примеру, в нашей стране масштабы реализации сорбционных технологий в системах очистки нефтезагрязненных вод на несколько порядков разнятся с зарубежной практикой. С учетом импорта потребление нефтесорбентов в России составляет всего 6-7,5 тыс. т в год. Если принять во внимание, что около $60 \%$ разлившейся нефти не собирается, $20 \%$ - устраняется с помощью механических средств (скиммерные устройства) и вручную, а средняя нефтеемкость сорбентов составляет 20-30 кг на 1 кг поглотителя, то средняя годовая емкость рынка сорбентов России для жидких углеводородов равняется приблизительно 110-130 тыс. т [3]. Необходима разработка новых технологических решений, направленных на расширение ассортимента дешевых сорбентов. В территориальных образованиях могут быть созданы производства сорбентов из распространенного местного сырья, особенно являющегося отходом.

Северо-Кавказский регион обладает собственными большими перспективными и пока не освоенными ресурсами. Интерес представляют золошлаковые отходы мусоросжигательных заводов [4], многотоннажные отходы агропромышленного комплекса. Использование подобного сырья позволяет одновременно решать проблему утилизации отходов и получения продуктов, применяемых в природоохранной деятельности $[5,6]$.

Биомасса сельскохозяйственных отходов (подсолнечной, рисовой, гречневой лузги и т.п.) представлена в основном полисахаридами с 5-6 углеродными атомами (целлюлоза - 30-40\% и гемицеллюлозы - 10-27\%) и полимерами с высокой степенью ароматизации (лигнин - 18-24\%). Практически все эти материалы имеют относительно высокое содержание углерода, низкую зольность порядка 2-3,5\% и характеризуются высоким выходом летучих соединений, то есть являются потенциальным сырьем для нефтесорбентов [7].

В целях получения сорбентов отходы подвергаются термомодифицированию. Оно заключается в их карбонизации в бескислородных условиях для удаления летучих соединений и развития первичной пористой структуры [8].

В ходе этого процесса происходит образование кокса либо полукокса с заданными физико-химическими свойствами (состав, структура, текстуpa, механические характеристики и т.п.). В свою очередь, выход кокса и его свойства определяются технологическими условиями отдельных стадий процесса. При этом химические механизмы трансформации различных растительных отходов имеют в достаточной мере общий характер. 


\section{Материалы и методы исследований}

В качестве сырья использовали подсолнечную лузгу. Ее карбонизацию проводили на лабораторной установке, основным элементом которой являлся вертикальный кварцевый реактор, помещенный в муфельную печь с регулируемым электронагревом. В установке также были организованы системы подачи газа-носителя (азота), охлаждения и сбора сконденсированной воды и смолистых продуктов.

Методика получения сорбентов состояла в следующем. Лузгу загружали в кварцевый реактор и помещали в холодную печь. Термообработку проводили в три этапа. На первом этапе лузгу сушили при $105-110^{\circ} \mathrm{C}$ в течение 30 мин., на втором - нагревали до температуры изотермической выдержки, которую варьировали от 200 до $600^{\circ} \mathrm{C}$, и выдерживали 15 мин. По окончании изотермической выдержки (третий этап) производили снижение температуры до 40оС и выгрузку карбонизата.

Применялись методы термического анализа. Они охватывают ряд смежных инструментальных методов, в которых устанавливается зависимость параметров какого-либо физического свойства вещества от температуры. Каждый параметр регистрируется как динамическая функция температуры. Данные представляются с помощью соответствующей кривой. Информация, которую дает термический анализ, отражает состояние структуры исследуемого материла и ее изменения, определяющие механизм термических превращений. Конкретный вид метода термического анализа определяется регистрируемым параметром и используемым измерительным прибором.

Для исследования сырья был проведен термогравиметрический анализ сорбентов (ТГ-ДТА анализ) на термоанализаторе SDT Q 600 (производитель TA-Instruments, США). На весы дериватографа помещали навеску (10-20 мг) в корундовом тигле. Кривые ДСК-ТГ регистрировали в режиме линейного подъема температуры со скоростью $10^{\circ} \mathrm{C} /$ мин. в интервале $20-800^{\circ} \mathrm{C}$ в токе сухого воздуха (100 мл/мин). Накопление и обработку дериватографической информации проводили с помощью пакета программ Universal Analysis 2000, входящего в комплектацию прибора.

Сорбционные характеристики полученных материалов, такие как нефтеемкость, водопоглощение, плавучесть, оценивались по ТУ 214-1094223803-95.

Пористая структура карбонизатов исследовалась на растровом электронном микроскопе РЭМ-106И методом сканирующей электронной микроскопии.

Изучение пористой структуры образцов проводили методом низкотемпературной адсорбции азота на приборе ASAP-2010 (производитель Micromeritics, США). Предобработка образцов включала вакуумирование при $80{ }^{\circ} \mathrm{C}$ до $4 \cdot 10^{-1}$ Па в течение суток. Адсорбцию $\mathrm{N}_{2}$ проводили при $77 \mathrm{~K}$. Изотермы регистрировали в виде зависимостей $\mathrm{V}_{\text {адсггаза }}\left(\mathrm{cm}^{3} / \Gamma\right)=\mathrm{f}\left(\mathrm{p} / \mathrm{p}_{0}\right)$. На ос- 


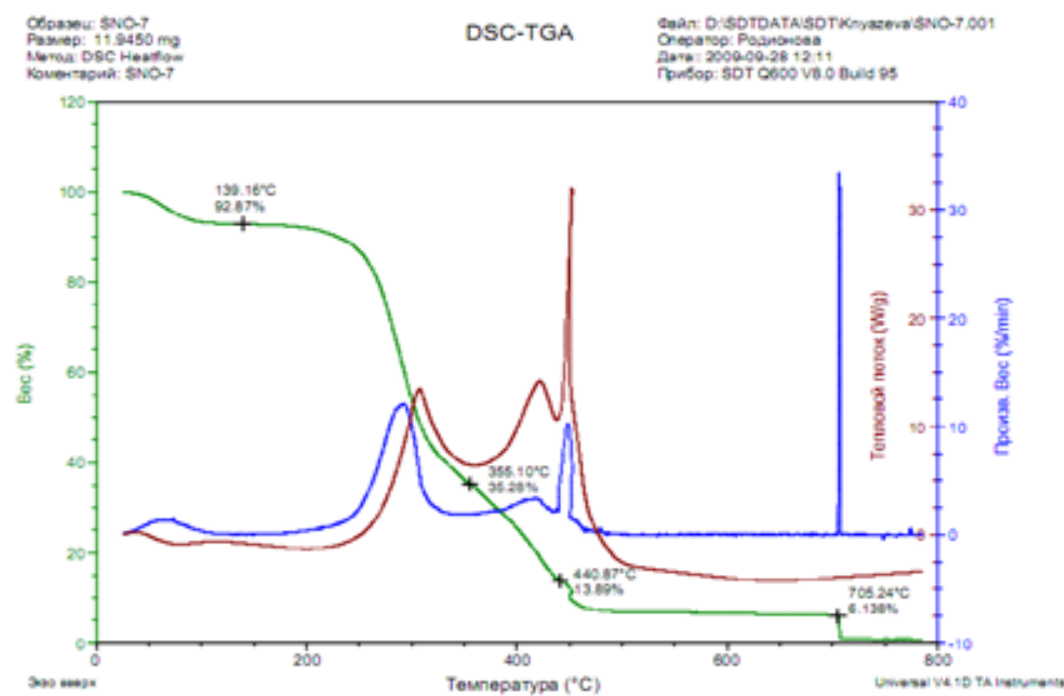

Рис. 1.

\section{Термограмма разложения лузги подсолнечной.}

Fig. 1. The thermogram of the decomposition of husk sunflower.

новании полученных изотерм адсорбции азота рассчитывали характеристики пористой структуры сорбентов с помощью стандартного программного обеспечения прибора.

\section{Результаты исследований и их обсуждение}

Получены зависимости изменения веса образца, теплового потока и производной веса от температуры. Термограмма разложения подсолнечной лузги представлена на рисунке 1.

Анализ термограммы свидетельствует о наличии в лузге некоторого количества воды, что подтверждается небольшим эндотермическим эффектом в диапазоне температур 90-200 ${ }^{\circ} \mathrm{C}$. При этом потери массы достигают 7-8\%, что весьма близко к значениям, полученным при определении влажности сырья. Заметная убыль веса регистрируется в диапазоне $250-450^{\circ} \mathrm{C}$. Она составляет 65-86\%. Потери массы соответствуют двум значительным пикам, отражающим выделение энергии при $280-350^{\circ} \mathrm{C}$ и $400-450^{\circ} \mathrm{C}$. В диапазоне от 450 до $700^{\circ} \mathrm{C}$ отмечается относительное постоянство веса и теплового потока, что свидетельствует об отсутствии заметных химических изменений в структуре сырья. Однако при $700-710{ }^{\circ} \mathrm{C}$ регистрируется резкое снижение веса образца до $6 \%$, что, вероятно, связано с разложением высококипящих компонентов. 


\begin{tabular}{l}
\hline 90 \\
\hline 80 \\
70 \\
60 \\
50 \\
40 \\
\hline 30 \\
20 \\
\hline
\end{tabular}

Рис. 2.

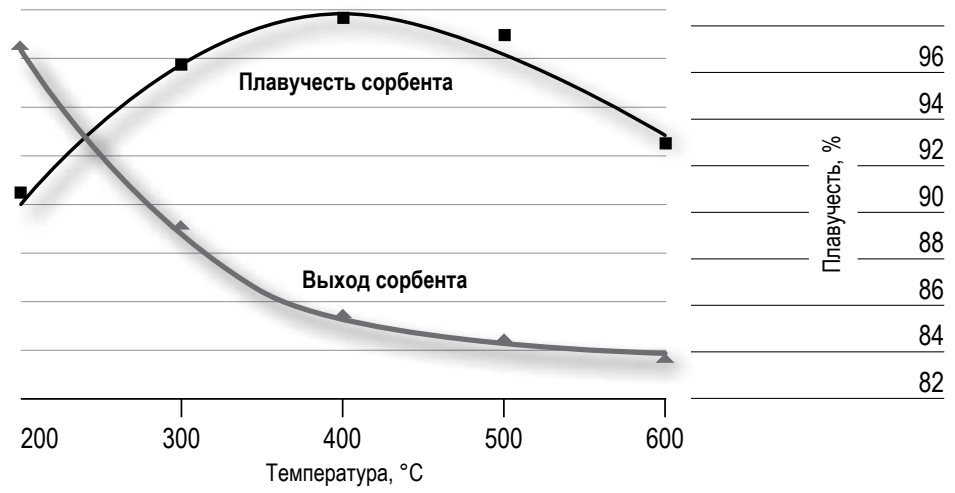

Зависимость выхода и плавучести сорбента от температуры карбонизации.

Fig. 2. Dependence of the yield and buoyancy of the sorbent on the temperature of carbonization.

Таким образом, с нашей точки зрения, процесс термического разложения растительных отходов в диапазоне $150-700^{\circ} \mathrm{C}$ состоит из двух стадий:

- низкотемпературной, протекающей при $200-350^{\circ} \mathrm{C}$, сопровождающейся дегидратацией сырья и его последующей карбонизацией и отличающейся выделением основной массы летучих продуктов;

- высокотемпературной, протекающей при температуре выше $400^{\circ} \mathrm{C}$ и ведущей к образованию плотной углеродной структуры с малым выходом.

В качестве примера графической интерпретации опытных данных на рисунках 2, 3 показана динамика изменения выхода, нефтеемкости, водопоглощения и плавучести сорбентов от температуры карбонизации.

Анализ экспериментальных данных, полученных при исследовании влияния температуры карбонизации на эксплуатационные характеристики сорбентов, позволяет сделать заключение, что во всех случаях выход продукта с увеличением температуры снижается. Причем основная потеря массы происходит в диапазоне $250-500^{\circ} \mathrm{C}$. При температуре выше $600{ }^{\circ} \mathrm{C}$ выход готового продукта составляет менее $30 \%$ масс.

В интервале $300-400^{\circ} \mathrm{C}$ наблюдается заметный рост адсорбционной емкости продукта по жидким углеводородам по сравнению с исходной лузгой. Увеличение поглотительной способности по нефти составляет 53-61 \%, по моторному маслу - 61-64\%, по дизельному топливу - 53-62\%. При температуре карбонизации $>400{ }^{\circ} \mathrm{C}$ отмечается снижение адсорбционной емкос- 


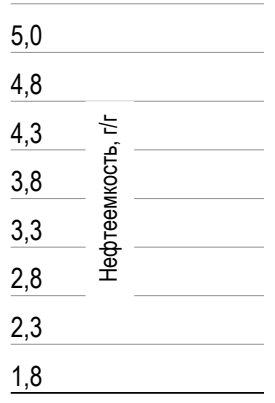

Рис. 3.

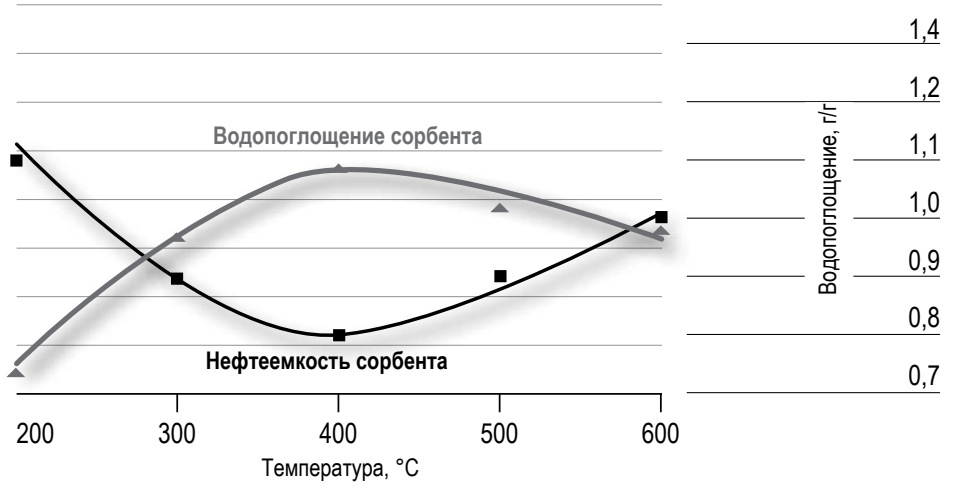

Зависимость нефте- и водопоглощения сорбента от температуры карбонизации.

Fig. 3. Dependence of oil and water adsorption of the sorbent on the temperature of carbonization.

ти адсорбентов на $12 \%$ по нефти и небольшой рост по моторному маслу - 7\% и дизельному топливу $-3 \%$.

При термообработке существенным образом меняется водопоглощение. Этот показатель качества сорбента не менее важен, чем нефтеемкость, потому что влияет на эффективность очистки.

В диапазоне $300-400^{\circ} \mathrm{C}$ водопоглощение по сравнению с необработанной лузгой снижается на $39 \%$, так как выделяющаяся смола создает водоотталкивающее олеофильное покрытие на поверхности углеродного сорбента. При более высокой температуре изотермической выдержки наблюдается некоторый рост данного показателя (на $25 \%$ по сравнению с водопоглощением в интервале $300-400^{\circ} \mathrm{C}$ ), что, вероятно, обусловлено выгоранием гидрофобных компонентов. Снижение водопоглощения, вызванное термообработкой лузги, отражается на способности сорбента оставаться на плаву при внесении в сточную воду или водоем. Так, плавучесть сорбентов, полученных в температурном интервале $300-400^{\circ} \mathrm{C}$, при сопоставлении с исходным материалом выше на $13 \%$. При более высокой температуре обработки лузги происходит понижение данного показателя примерно на $5 \%$.

Изучена пористая структура полученных карбонизатов. На рисунке 4 представлены микрофотографии срезов термообработанной лузги.

Проведенные исследования показали, что карбонизованные образцы имеют фибриллярное строение, что свидетельствует о сохранении морфологической структуры исходного целлюлозного волокна лузги.

Пористая структура сорбентов оказывает существенное влияние на их эксплуатационные характеристики, в первую очередь, на емкость поглоще- 

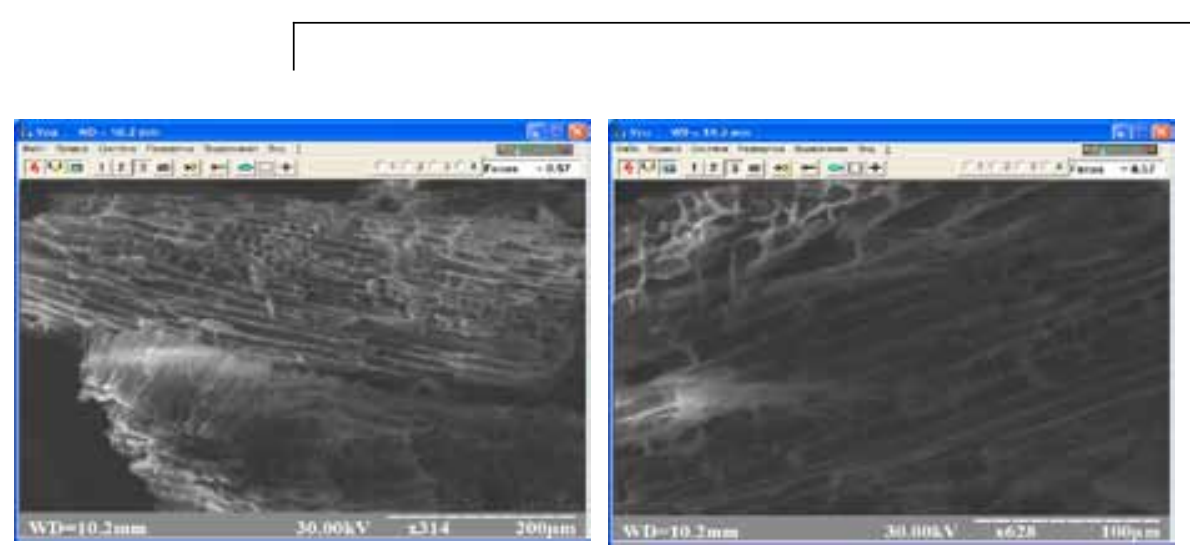

Puc. 4.

\section{Электронно-микроскопические снимки образцов после карбонизации при $350^{\circ} \mathrm{C}$.}

Fig. 4. Electron microscopic images of samples after carbonization at $350^{\circ} \mathrm{C}$.

ния, время сорбции, возможность удержания и десорбции нефтепродукта, а также плавучесть и возможность захвата вместе с нефтью части воды. Микропористые поглотители малоэффективны для поглощения крупных молекул углеводородов. Широкопористые сорбенты быстрее впитывают нефть и быстрее ее отдают при отжиме, однако хуже удерживают легкие нефтепродукты (бензин, дизельное топливо).

В качестве объектов исследования использовались различные модификации сорбентов на основе рисовой (РЛ), подсолнечной (ПЛ) и гречневой лузги (ГЛ), полученные в ходе как обычной термической обработки, так и дополнительно подвергшиеся предварительной реагентной химической трансформации и грануляции со связующим. Условия получения и величины поверхности сорбентов представлены в таблице 1.

Из данных таблицы 1 следует, что исходные образцы РЛ, ГЛ и ПЛ обладают небольшой поверхностью, величины которой составляют 0,2-1,3 м²/г. При этом внешний вид изотерм различается (рис. 5).

Для образцов ГЛ и ПЛ изотерма адсорбции азота соответствует изотермам III типа по классификации Брунауэра, а именно адсорбции на непористых телах. Она отражает отсутствие микропор. Плавный подъем в области относительных давлений $\mathrm{P} / \mathrm{P}_{0}$ от 0,5 до 0,9 указывает на наличие в образце мезопор. Форма гистерезисной петли по классификации де Бура соответствует типу Н3, т.е. поры сорбента являются цилиндрическими с почти параллельны- 
Таблица 1.

УСЛОВИЯ ПОЛУЧЕНИЯ И ПОВЕРХНОСТИ СОРБЕНТОВ

Table 1. CONDITIONS FOR THE PRODUCTION AND SURFACE OF SORBENTS

\begin{tabular}{|c|c|c|c|}
\hline Исходная лузга & Обработки & $\begin{array}{l}\text { Поверхность, } \\
\mathrm{M}^{2} / \mathrm{r}\end{array}$ & $\begin{array}{l}\text { Поверхность } \\
\text { микропор, } \\
\text { м²/г }^{2}\end{array}$ \\
\hline \multirow[t]{2}{*}{ Рисовая } & - & 0,9 & 0,4 \\
\hline & карбонизация при $300^{\circ} \mathrm{C}$ & 170 & 130 \\
\hline \multirow[t]{2}{*}{ Гречневая } & - & 0,2 & - \\
\hline & карбонизация при $600^{\circ} \mathrm{C}$ & 0,9 & - \\
\hline \multirow[t]{7}{*}{ Подсолнечная } & - & 1,3 & - \\
\hline & карбонизация при $350^{\circ} \mathrm{C}$ & 3,7 & - \\
\hline & $\begin{array}{l}\text { добавка гидроксида кальция } \\
\text { и карбамида с последующей } \\
\text { карбонизацией при } 400^{\circ} \mathrm{C}\end{array}$ & 3,0 & - \\
\hline & добавка ПВА & 2,3 & - \\
\hline & $\begin{array}{l}\text { добавка ПВА с последующей } \\
\text { карбонизацией при } 280^{\circ} \mathrm{C}\end{array}$ & 2,9 & - \\
\hline & $\begin{array}{l}\text { добавка ПВА с последующей } \\
\text { карбонизацией при } 300^{\circ} \mathrm{C}\end{array}$ & 2,7 & - \\
\hline & $\begin{array}{l}\text { гранулированный комплексный } \\
\text { карбонизат из нефтешлама, } \\
\text { лузги и ПВА после термообработки } \\
\text { при } 300^{\circ} \mathrm{C}\end{array}$ & 5,1 & - \\
\hline
\end{tabular}

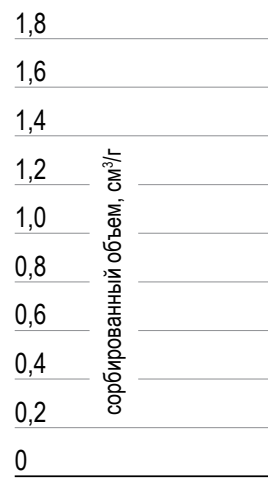

Рис. 5.

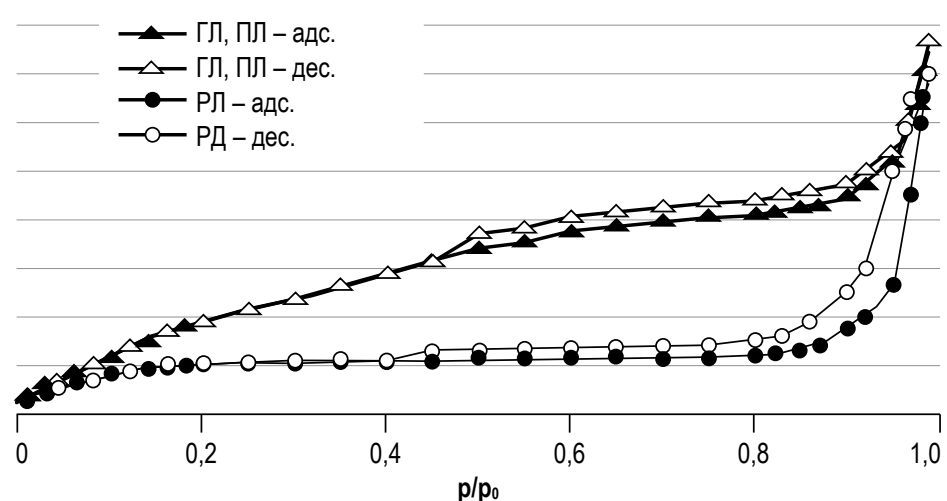

Изотермы низкотемпературной адсорбции азота на РЛ, ГЛ и Пл.

Fig. 5. Isotherms by low-temperature nitrogen adsorption on $\mathrm{RH}$, $\mathrm{BH}$ and $\mathrm{SH}$. 


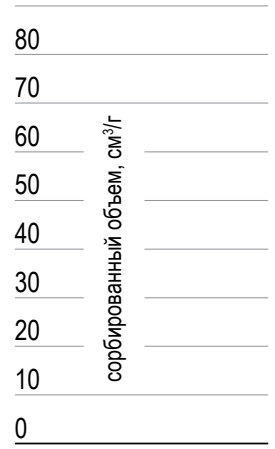

$\underline{0}$

Рис. 6.

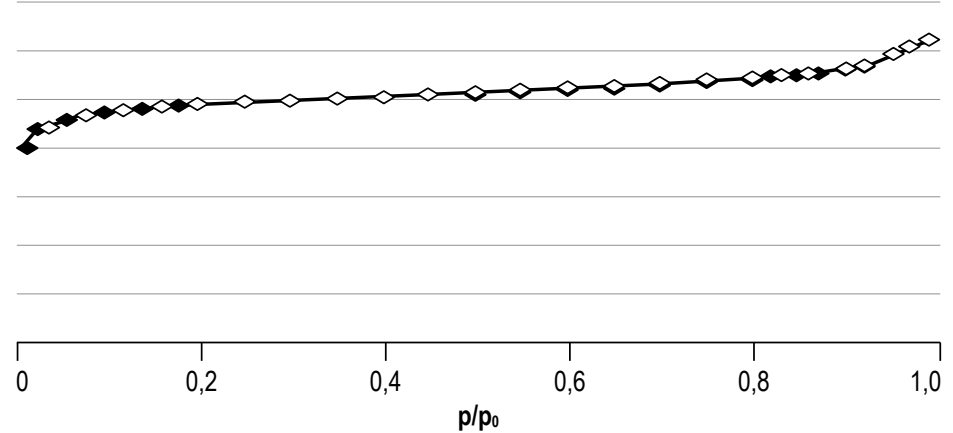

Изотерма низкотемпературной адсорбции азота на карбонизированной рисовой лузге.

Fig. 6. Isotherm by low-temperature nitrogen adsorption on carbonized sunflower husk.

ми стенками. Изотерма имеет наклон, значит, величина адсорбции возрастает с увеличением давления. Возрастание можно объяснить капиллярной конденсацией азота в мезо- и макропорах внутри гранулы карбонизата, а также адсорбцией на внешней поверхности гранулы.

Для образца РЛ изотерма соответствует IV типу, т.е. адсорбции на микропористых материалах. Это подтверждается наличием значительной доли микропор, величина поверхности микропор составила $0,4 \mathrm{~m}^{2} / \Gamma$. Процедура карбонизации гречневой и подсолнечной лузги привела к увеличению поверхности в 3-4 раза. При этом внешний вид изотерм не менялся и соответствовал изотермам адсорбции на непористых телах (рис. 5). Наблюдаемое увеличение поверхности в процессе карбонизации может быть связано с увеличением дисперсности частиц, например, в результате растрескивания.

Карбонизация рисовой лузги позволяет получить сорбент с очень развитой поверхностью (рис. 6, табл. 1).

В процессе карбонизации поверхность образца увеличилась от 0,9 до $170 \mathrm{M}^{2} /$ г. Наблюдаемый рост поверхности может быть связан, в первую очередь, с особенностями химического состава рисовой лузги, а именно с преобладанием в качестве основного компонента оксида кремния. Необходимо заметить, что после карбонизации рисовой лузги образец остается микропористым, сохраняется тип изотермы (рис. 6). Значительная величина поверхности 


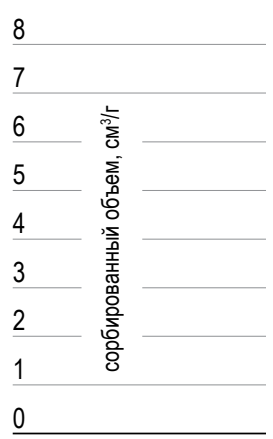

Puc. 7.

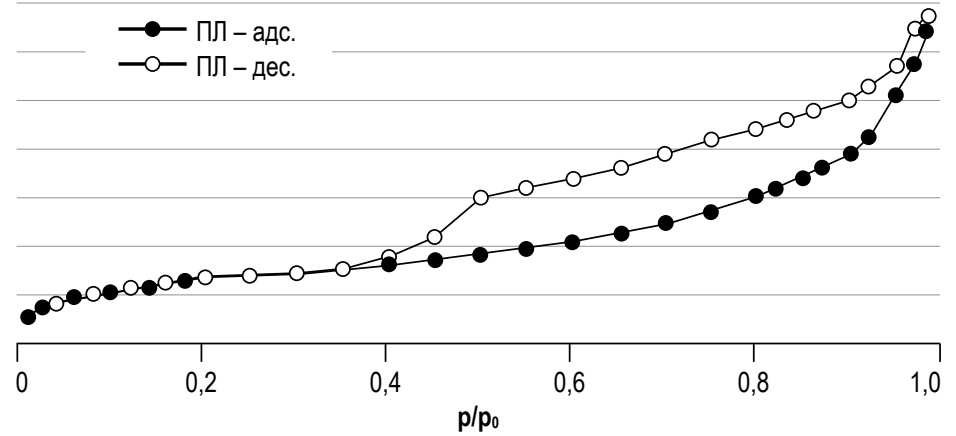

Изотерма низкотемпературной адсорбции азота на гранулированном комплексном карбонизате из нефтешлама, подсолнечной лузги и ПВА после термообработки при $300{ }^{\circ} \mathrm{C}$.

Fig. 7. Isotherm by low-temperature nitrogen adsorption on granulated complex carbonate from oil sludge, sunflower husk and PVA after heat treatment at $300^{\circ} \mathrm{C}$.

микропор $\left(130 \mathrm{~m}^{2} / \Gamma\right)$ соответствует таким известным микропористым сорбентам, как цеолиты.

Таким образом, рисовая лузга пригодна для получения микропористых сорбентов с развитой поверхностью или композитных сорбентов с комбинированной поверхностью. Сорбенты на ее основе могут быть использованы для очистки воды от тяжелых металлов и углеводородов.

На примере сорбентов на основе подсолнечной лузги изучено влияние различных обработок на величину поверхности получаемых материалов. Использование для грануляции нефтяного шлама позволило увеличить поверхность сорбента до $5,1 \mathrm{~m}^{2} / \Gamma$ и привело к изменению внешнего вида изотермы (рис. 7).

Изотермы такого вида относят к IV типу. Наличие плавного подъема в области относительных давлений $\mathrm{p} / \mathrm{p}_{0}$ от 0,5 до 0,9 указывает на присутствие в образце мезопор, средний диаметр которых составляет 10 нм. Петля гистерезиса показывает, что мезопоры имеют форму «горлышка бутылки», тогда как небольшой гистерезис на изотермах исходной и карбонизированной подсолнечной лузги (рис. 5) указывает на существование щелевидных пор. Очевидно, наличие мезопор в этом случае связано с присутствием нефтяного шлама, т.к. использование ПВА и карбонизации при $300^{\circ} \mathrm{C}$ в других случаях не приводило к подобным изменениям изотерм. 
Гранулированные сорбенты на основе лузги подсолнечной, содержащие нефтешлам, могут быть использованы для очистки воды от органических загрязнителей с меньшим размером молекул, чем у нефти, например, органических красителей.

\section{Выводы}

Сравнительный анализ выявил прямую зависимость эксплуатационных характеристик сорбентов от параметров пористой структуры, формируемой в ходе термомодификации. Так, рост нефтепоглощения в интервале обработки $300-400^{\circ} \mathrm{C}$ объясняется возрастанием удельной поверхности по сравнению с исходным сырьем. С увеличением температуры карбонизации растет объем макропор, отвечающих за поглощение высокомолекулярных соединений нефти, а также мезопор, поскольку увеличивается доля поглощенного дизельного топлива. При температуре пиролиза меньше $300{ }^{\circ} \mathrm{C}$ эксплуатационные показатели сорбентов заметно ниже, так как не развивается достаточно высокая пористость. При температуре выше $400^{\circ} \mathrm{C}$ отмечается снижение выхода готового продукта, уменьшение его механической прочности. В этой связи температурный интервал $300-400^{\circ} \mathrm{C}$ можно считать оптимальным для получения сорбентов на основе растительных отходов, а в зависимости от целей очистки стоков возможно улучшение эксплуатационных характеристик поглотителей за счет реагентной модификации.

\section{Библиографический список}

1. Каменщиков Ф. А., Богомольный Е. И. Нефтяные сорбенты. М.; Ижевск: НИЦ «Регулярная и хаотическая динамика», 2005. 268 c.

2. Дремичева Е. С. Эфрфективность сорбционных материалов для сбора нефтепродуктов с поверхности водоемов // Защита окружающей среды в нефттегазовом комплексе. 2017. № 1. С. 35-39.

3. Петов Н. Разливанное море разливов // Нефть России. 2009. №5. C. 77-78.

4. Калиниченко А. Ю., Кудымова А. А. Очистка сточных вод от тяжелых металлов адсорбентом на основе шлака Пятигорского теплоэнергетического комплекса // Материалы международной научно-технической конференции «Защита окружающей среды от экотоксикантов» (14-15 апреля 2014 г.). Уфа: РИЦ УГНТУ, 2014. C. 50-54.

5. Овчаров С. Н., Долгих (Ларина) О. Г., Овчаров Д. С. Адсорбционные технологии и средства ликвидации нефтяного загрязнения воды // Вестник Северо-Кавказского федерального университета. 2013. № 3 (36). С. 69-74.

6. Исследование характеристик модифицированных сорбентов серий «Униполимер-М» и «Унисорб» / В.М. Мелкозеров, С.И. Васильев, Д.Н. Журавлев, Л.А. Лапушова, А. С. Федото- 
ва // Защита окружающей среды в нефтегазовом комплексе. 2017. №3. С. 13-17.

7. Новые эффеективные сорбенты (поглотители) на основе шелухи риса для сбора проливов и очистки вод / А. А. Хохряков, А. А. Ежелев, С.В. Половцев, С.А. Керножицкая, В. Б. Мошковский // Вода и экология: проблемы и решения. 2007. №3. С. 4652.

8. Долгих (Ларина) О.Г., Овчаров С.Н. Получение нефтесорбентов карбонизацией лузги подсолнечника // Экология и промышленность России. 2009. № 11. С 4-7.

\section{References}

1. Kamenshchikov F. A., Bogomol'nyj E. I. Neftyanye sorbenty (Oil sorbent products). M.; Izhevsk: NIC «Regulyarnaya i haoticheskaya dinamika», 2005. 268 p.

2. Dremicheva E. S. Effektivnost' sorbtsionnykh materialov dlya sbora nefteproduktov s poverkhnosti vodoyemov (The efficiency of sorption materials for the collection of oil products from the surface of reservoirs) // Zashchita okruzhayushey sredy v neftegazovom komplekse. 2017. № 1. Pp. 35-39.

3. Petov N. Razlivannoe more razlivov (Spilled sea of overflows) // Neft' Rossii. 2009. № 5. Pp. 77-78.

4. Kalinichenko A. Yu., Kudymova A. A. Ochistka stochnyh vod ot tyazhelyh metallov adsorbentom na osnove shlaka Pyatigorskogo teploehnergeticheskogo kompleksa (Treatment of waste water from heavy metals by adsorbent based on slag of Pyatigorsk thermal power complex) // Materialy mezhdunarodnoj nauchno-tekhnicheskoj konferencii «Zashchita okruzhayushchej sredy ot ehkotoksikantov» (14-15 aprelya 2014 g.). Ufa: RIC UGNTU, 2014. Pp. 50-54.

5. Ovcharov S. N., Dolgikh (Larina) O. G., Ovcharov D. S. Adsorbcionnye tekhnologii i sredstva likvidacii neftyanogo zagryazneniya vody (Adsorption technologies and elimination methods of the oil pollution of water) // Vestnik Severo-Kavkazskogo federal'nogo universiteta. 2013. № 3 (36). Pp. 69-74.

6. Issledovaniye kharakteristik modifitsirovannykh sorbentov seriy «Unipolimer-M» $\mathrm{i}$ «Unisorb» (The study of the characteristics of «Unipolymer-M» and "Unisorb» modified sorbents) / V. M. Melkozerov, S. I. Vasil'ev, D. N. Zhuravlev, L. A. Lapusheva, A. S. Fedotova // Zashchita okruzhayushey sredy v neftegazovom komplekse. 2017. № 3. Pp. 13-17.

7. Novye effektivnye sorbenty (poglotiteli) na osnove shelukhi risa dlya sbora prolivov i ochistki vod (New efficient sorbents (sinks) on the basis of rice husk to collect spills and water purification) / A.A. Khokhryakov, A. A. Ezhelev, S. V. Polovtsev, S. A. Kernozhitskaya, V.B. Moshkovskiy //Voda i ecologiya: problemy i resheniya. 2007. № 3. Pp 46-52.

8. Dolgikh (Larina) O. G., Ovcharov S. N. Polucheniye neftesorbentov karbonizatsiyey luzgi podsolnechnika (Production of oil sorbents 
by carbonization of sunflower husk) // Ekologiya i promyshlennost' Rossii. 2009. № 11. Pp 4-7.

\section{6 авторах}

Ларина Оксана Геннадьевна, кандидат технических наук, доцент кафедры технологии переработки нефти и промышленной экологии института нефти и газа ФГАОУ ВО «Северо-Кавказский федеральный университет», г. Ставрополь, просп. Кулакова, 16/1, Researcher ID: O-3787-2018. Телесрон: (8652) 33-06-60. E-mail: oksdolgikh@ yandex.ru.

Овчаров Сергей Николаевич, доктор технических наук, профессор, профессор кафедры технологии переработки нефти и промышленной экологии института нефти и газа ФГАОУ ВО «Северо-Кавказский федеральный университет», г. Ставрополь, просп. Кулакова, 16/1, Scopus ID: 6506180690. Телефон: (8652) 33-06-60. E-mail: osn_tpnpe@mail.ru.

Калиниченко Андрей Юрьевич, кандидат технических наук, доцент, заведующий кафедрой технологии переработки нефти и промышленной экологии института нефти и газа ФГАОУ ВО «Северо-Кавказский федеральный университет», г. Ставрополь, просп. Кулакова, 16/1. Телефон: (8652) 33-06-60. E-mail: andrey026rus@ yandex.ru.

\section{About the authors}

Larina Oksana Gennadyevna, candidate of technical sciences, associate professor of chair of oil refining technology and industrial ecology institute of oil and gas of FGAOU VO «North Caucasus Federal University», Stavropol, 16/1 Kulakov avn. Researcher ID: O-3787-2018. Phone: (8652) 33-06-60. E-mail: oksdolgikh@yandex.ru.

Ovcharov Sergey Nikolaevich, doctor of technical sciences, professor, professor of chair of oil refining technology and industrial ecology institute of oil and gas of FGAOU VO «North Caucasus Federal University», Stavropol, 16/1 Kulakov avn. Scopus ID: 6506180690. Phone: (8652) 33-06-60. E-mail: osn tpnpe@mail.ru.

Kalinichenko Andrey Yuryevich, candidate of technical sciences, associate professor, head of chair of oil refining technology and industrial ecology institute of oil and gas of FGAOU VO «North Caucasus Federal University», Stavropol, 16/1 Kulakov avn. Phone: (8652) 33-06-60. E-mail: andrey026rus@yandex.ru. 